Volume 1, Nomor 2, Oktober 2020, 75-84

JTTM: Jurnal Terapan Teknik Mesin

p ISSN 2721-5377 | e ISSN 2721-7825

\title{
MODIFIKASI GEARBOX CLOSE RATIO UNTUK MENINGKATKAN AKSELERASI SEPEDA MOTOR KAWASAKI NINJA RR 150CC
}

\section{MODIFICATION OF GEARBOX CLOSE RATIO TO IMPROVE ACCELERATION OF KAWASAKI NINJA RR 150CC MOTORCYCLES}

\author{
Hendly Kevin Ramadhony Putra ${ }^{1}$, Awang Surya ${ }^{2 *}$ \\ 1,2* Program Studi Teknik Mesin, Sekolah Tinggi Teknologi Muhammadiyah Cileungsi \\ 1,2* Jl. Anggrek, No 25, Komplek PT.SC, Cileungsi, Bogor, Jawa Barat, Indonesia 16820 \\ * Koresponden Email: awang.surya @ sttmcileungsi.ac.id
}

\begin{abstract}
Abstrak. Karakter sepeda motor terbagi menjadi dua tipe yaitu sepeda motor akselerasi dan sepeda motor top speed. Karakter sepeda motor top speed adalah sepeda motor yang dapat memiliki kecepatan maksimal yang tinggi dan dapat menempuh jarak yang panjang dengan putaran mesin yang tinggi, namun akselerasinya kurang bagus. Modifikasi sepeda motor dilakukan pemilik dengan tujuan menyempurnakan penampilan dan meningkatkan performa sepeda motor. Di antara tujuan modifikasi adalah meningkatkan performa akselerasi sepeda motor, karena sepeda motor yang dimiliki mempunyai top speed yang tinggi tetapi kurang baik dalam berakselerasi. Sedangkan situasi jalanan terutama di kota besar yang sering sering macet tidak memungkinkan untuk menggunakan top speed yang tinggi. Tujuan penelitian ini untuk mendapatkan performa akselerasi. Dalam hal ini dilakukan studi kasus pada sepeda motor Kawasaki Ninja RR 150cc. Metode yang digunakan dalam penelitian ini adalah penelitian eksperimen, yaitu dengan membandingkan performa sepeda motor yang memakai gearbox standar dengan sepeda motor yang menggunakan gearbox hasil modifikasi. Simpulan yang didapat dari penelitian menunjukkan bahwa gearbox modifikasi telah memberikan hasil yang lebih baik dibanding dengan gearbox standar. Untuk mencapai kecepatan $60 \mathrm{~km} / \mathrm{jam}$ dari kecepatan $0 \mathrm{~km} / \mathrm{jam}$ pada gearbox standar dibutuhkan waktu 3,5 detik, sedangkan pada gearbox modifikasi dibutuhkan waktu 2,7 detik. Untuk mencapai kecepatan $100 \mathrm{~km} / \mathrm{jam}$ dari kecepatan $0 \mathrm{~km} / \mathrm{jam}$ pada gearbox standar dibutuhkan waktu 7,5 detik sedangkan pada gearbox modifikasi dibutuhkan waktu 6,5 detik. Dari hasil pengujian di jalan didapat hasil bahwa waktu yang dibutuhkan untuk mencapai jarak 100 meter pada gearbox standar dibutuhkan waktu 6,2 detik, sedangkan pada gearbox modifikasi dibutuhkan waktu 5,1 detik. Untuk mencapai jarak 200 meter pada gearbox standar dibutuhkan waktu 10 detik sedangkan pada gearbox modifikasi dibutuhkan waktu 9.5 detik.
\end{abstract}

Kata kunci: Gearbox, Sepeda Motor, Modifikasi

\begin{abstract}
Motorcycle characters are divided into two types, namely accelerated motorbikes and top speed motorbikes. The character of a top speed motorcycle is a motorcycle that can have a high maximum speed and can cover long distances with high engine speed, but the acceleration is not good. Motorcycle modifications are carried out by owners with the aim of improving the appearance and increasing the performance of the motorbike. Among the objectives of the modification is to improve the acceleration performance of the motorcycle, because the motorbike owned has a high top speed but is not good at accelerating. Meanwhile, the road situation, especially in big cities, which are often jammed, makes it impossible to use a high top speed. The aim of this research is to get acceleration performance. In this case, a case study was carried out on the Kawasaki Ninja RR 150cc motorcycle. The method used in this research is experimental research, namely by comparing the performance of a motorcycle that uses a standard gearbox with a motorcycle that uses a modified gearbox. The conclusions obtained from the study indicate that the modified gearbox has given better results than the standard gearbox. To reach a speed of $60 \mathrm{~km} / \mathrm{h}$ from a speed of $0 \mathrm{~km} / \mathrm{h}$ on a standard gearbox it takes 3.5 seconds, while in a modified gearbox it takes 2.7 seconds. To reach a speed of $100 \mathrm{~km} / \mathrm{h}$ from a speed of 0 $\mathrm{km} / \mathrm{h}$ on a standard gearbox it takes 7.5 seconds while in a modified gearbox it takes 6.5 seconds. From the test results on the road, it is found that the time needed to reach a distance of 100 meters on a standard gearbox takes 6.2 seconds, while in a modified gearbox it takes 5.1 seconds. To reach a distance of 200 meters on a standard gearbox it takes 10 seconds while in a modified gearbox it takes 9.5 seconds.
\end{abstract}

Keywords: Gearbox, Motorcycle, Modification

JTTM: Jurnal Terapan Teknik Mesin is licensed under a Creative Commons AttributionNonCommercial 4.0 International License. 
Modifikasi Gearbox Close Ratio Untuk Meningkatkan Akselerasi Sepeda Motor Kawasaki Ninja RR 150CC

\section{PENDAHULUAN}

Peran transportasi dalam memberikan akses terhadap barang dan jasa sangat esensial bagi kehidupan seseorang, terutama kelompok marginal. Solusi umum untuk meningkatkan aksesibilitas masyarakat adalah dengan memberikan pelayanan transportasi publik. Namun dalam kondisi rendahnya pelayanan transportasi publik, kepemilikan kendaraan pribadi menjadi salah satu solusi yang tidak dapat dihindarkan. Sepeda motor, dengan harganya yang relatif murah dan fleksibilitas yang ditawarkan kendaraan pribadi, menjadi pilihan banyak masyarakat dengan pendapatan menengah-rendah [1].

Di banyak negara berkembang, sepeda motor semakin menjadi alat transportasi umum terutama di kalangan penduduk perkotaan berpenghasilan rendah [2] di Indonesia juga tidak berbeda. Salah satu alat transportasi yang paling banyak diminati penduduk Indonesia adalah sepeda motor. Hampir setiap keluarga memiliki sepeda motor [3]. Badan Pusat Statistik yang menyatakan bahwa jumlah sepeda motor di negara Indonesia pada tahun 2017 mencapai 113.030.793 unit [4]. Hal ini karena menggunakan sepeda motor memiliki keuntungan dibanding moda transportasi lain. Mengendarai sepeda motor dapat mempersingkat waktu tempuh perjalanan. Kondisi jalan raya di kota-kota besar yang sering macet relatif bisa diterobos dengan sepeda motor. Dari sisi biaya penggunaan sepeda motor lebih hemat. Dengan satu liter bahan bakar bisa menempuh beberapa puluh kilometer. Faktor lain yang juga mendukung meningkatnya penggunaan sepeda motor di kalangan masyarakat yakni mudahnya masyarakat membeli sepeda motor dengan pembayaran secara kredit [5].

Konsumen pada umumnya memilih merek dan jenis sepeda motor dengan tujuan-tujuan tertentu. Ada konsumen yang memilih sepeda motor untuk peruntukannya. Ada yang memilih karena modelnya. Ada juga yang memilih sepeda motor karena tenaga sepeda motor tersebut. Serta masih banyak lagi pertimbangan yang lain. Yang tidak kalah pentingnya adalah persepsi harga serta kualitas produk [6].

Pada kenyataannya banyak para pemilik sepeda motor yang tidak puas dengan sepeda motor yang dimilikinya. Tetapi mereka tidak mengambil keputusan untuk mengganti atau membeli sepeda motor baru. Mungkin karena pertimbangan biaya dan lain-lain. Maka kemudian terlahir kegiatan melakukan perubahan pada sepeda motor atau yang sering disebut juga dengan istilah modifikasi sepeda motor.

Secara umum karakter sepeda motor terbagi menjadi dua tipe yaitu sepeda motor akselerasi dan sepeda motor top speed. Karakter sepeda motor top speed atau disebut juga top end power dapat didefinisikan sebagai sepeda motor yang dapat memiliki kecepatan maksimal yang tinggi dan dapat menempuh jarak yang panjang dengan putaran mesin yang tinggi, namun akselerasinya kurang bagus. 
Secara umum modifikasi sepeda motor dilakukan dengan tujuan yaitu menyempurnakan penampilan dan meningkatkan performa sepeda motor misalnya daya motor [7]. Modifikasi bertujuan untuk mendapatkan kinerja yang lebih baik daripada system yang standar [8].

Tujuan dari modifikasi ini untuk meningkatkan performa akselerasi sepeda motor, karena merasa sepeda motor yang dimiliki mempunyai top speed yang tinggi tetapi kurang baik dalam berakselerasi. Sedangkan situasi jalanan terutama di kota besar yang sering sering macet tidak memungkinkan untuk menggunakan top speed yang tinggi. Jadi para pemilik sepeda motor seringkali justru memerlukan akselerasi yang cepat atau bagus.

Penelitian ini dilakukan dengan tujuan untuk membandingkan performance gearbox sepeda motor hasil modifikasi dengan gearbox standar. Dalam hal ini dilakukan studi kasus pada sepeda motor Kawasaki Ninja RR 150cc.

\section{METODE}

Penelitian ini adalah penelitian eksperimen, yaitu penelitian untuk menunjukkan hubungan sebab akibat antar veriabel [9]. Cara yang dilakukan adalah dengan membandingkan performa sepeda motor yang memakai gearbox standar dengan sepeda motor yang menggunakan gearbox hasil modifikasi. Sedangkan langkah-langkah yang dilakukan dalam penelitian ini seperti terlihat di dalam diagram alir pada gambar 1.

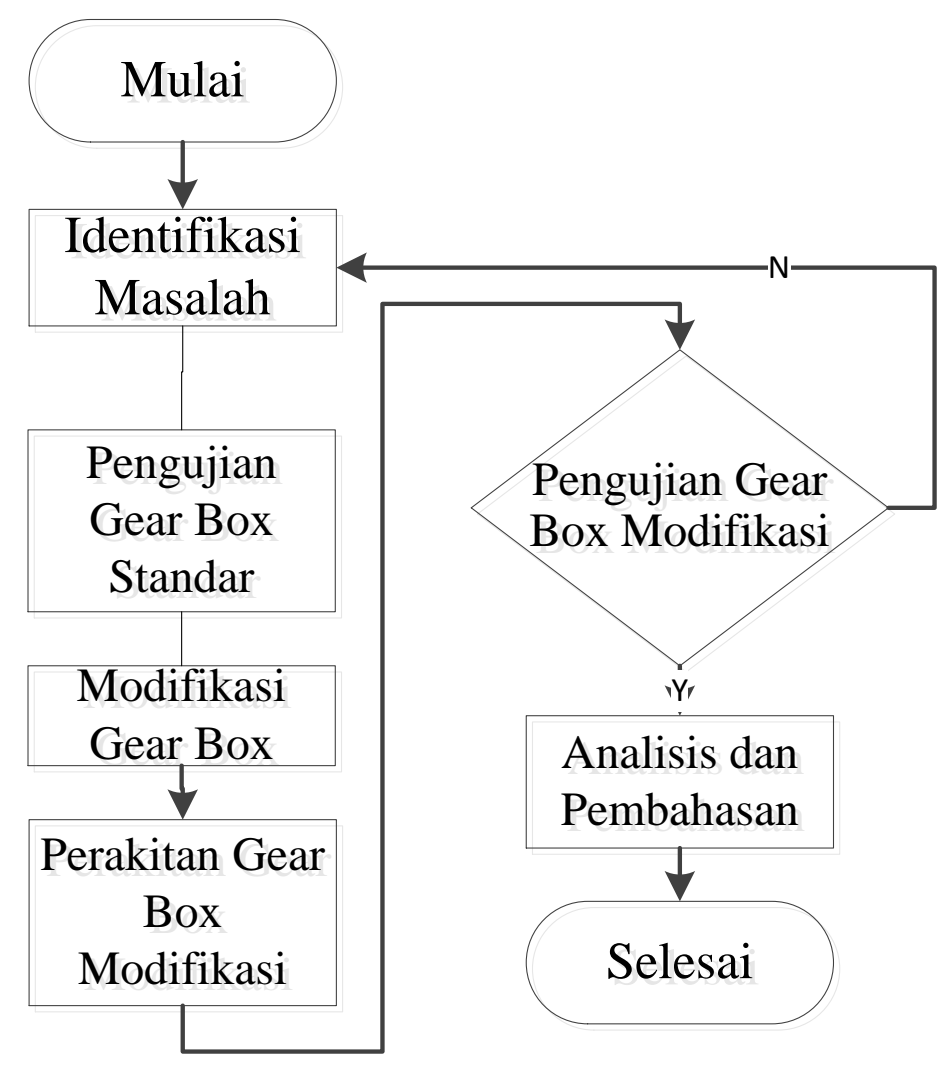

Gambar 1. Diagram alir metode penelitian 
Modifikasi Gearbox Close Ratio Untuk Meningkatkan Akselerasi Sepeda Motor Kawasaki Ninja RR 150CC

\subsection{Modifikasi Gearbox Close Ratio}

Di dalam melakukan modifikasi ada beberapa tahap yang diperlukan.Tahap pertama adalah penentuan jenis gearbox dan batasan-batasan dalam memodifikasi awal gearbox. Berikut ini adalah rencana modifikasi yang akan dilakukan pada gearbox close ratio.

- Gearbox close ratio yang akan dirancang memiliki batas shifting gear rpm yang tinggi jaraknya pada tingkat percepatan awal atau low gear (gear speed $1^{\text {st }}$ dan $2^{\text {nd }}$ ).

- Gearbox close ratio akan dirancang memiliki perbandingan rasio yang lebih ringan (light gear ratio) jika dibandingkan dengan gearbox standar Kawasaki Ninja RR 150cc pada gear speed 1, dan 2, lalu untuk tingkat percepatan pada gear speed 4, 5, dan 6 akan diberikan (heavy gear ratio).

- Gear speed $2^{\text {nd }}$ harus berkarakter low gear.

- Perbandingan rasio gear speed $1^{\text {st }}$ harus minimal 2 (nominal gear ratio), maksimal seperti ukuran standar.

- $\quad$ Top gear atau gear speed $6^{\text {th }}$ harus berkarakter overdrive.

Tahap yang kedua adalah menentukan jumlah mata roda gigi gearbox close ratio dengan langkahlangkah.

- Berdasarkan torsi dan horse power yang dihasilkan atau disediakan oleh mesin sepeda motor Kawasaki Ninja RR 150cc.

- Kemudian menentukan batas atau limit putaran mesin (rpm) untuk perpindahan tingkat kecepatan (shifting gear rpm), dengan memperhitungkan gear ratio per tingkat kecepatannya.

Tabel 1. Shifting gear RPM gearbox close ratio

\begin{tabular}{ll}
\hline Gear Speed & Shifting Gear RPM \\
\hline Gear Speed 1st & $5300 \mathrm{rpm}$ \\
Gear Speed 2st & $7000 \mathrm{rpm}$ \\
Gear Speed 3st & $8200 \mathrm{rpm}$ \\
Gear Speed 4st & $9500 \mathrm{rpm}$ \\
Gear Speed 5st & $1100 \mathrm{rpm}$ \\
Gear Speed 6st & $11500 \mathrm{rpm}$ \\
\hline
\end{tabular}

Lalu untuk menentukan jumlah mata pada setiap roda gigi gearbox, dipilih yang mendekati hasil perhitungan dengan menggunakan rumus mencari perbandingan rasio. Perbandingan rasio (terhadap putaran mesin), $(i)=\frac{N 1}{N 2}$

- Perbandingan rasio, (i) adalah perbandingan rasio antara roda gigi penggerak (drive gear) dengan roda gigi digerakkan (driven gear). 
- $\quad \mathrm{N} 1$ adalah jumlah putaran mesin per menit (rpm) maksimum pada batas aman mesin sepeda motor Kawasaki Ninja RR 150cc, yaitu 11000 rpm sebagai putaran mesin tertinggi yang aman.

- $\quad$ N2 adalah batas putaran mesin untuk melakukan perpindahan tingkat percepatan (shifting gear rpm).

Pada tabel 2 tentang jumlah mata roda gigi pada setiap tingkat percepatan untuk gearbox close ratio, yang perbandingan rasionya hampir mendekati perbandingan rasio hasil perhitungan diatas.

Tabel 2. Roda gigi pada gearbox close ratio dan perbandingan rasio

\begin{tabular}{cccc}
\hline Gear Speed & Gear Drive & Gear Driven & Gear Ratio \\
\hline Gear Speed 1st & $15 \mathrm{~T}$ & $31 \mathrm{~T}$ & 2.066 \\
Gear Speed 2nd & $18 \mathrm{~T}$ & $28 \mathrm{~T}$ & 1.555 \\
Gear Speed 3rd & $18 \mathrm{~T}$ & $24 \mathrm{~T}$ & 1.333 \\
Gear Speed 4th & $22 \mathrm{~T}$ & $25 \mathrm{~T}$ & 1.136 \\
Gear Speed 5th & $23 \mathrm{~T}$ & $23 \mathrm{~T}$ & 1.000 \\
Gear Speed 6th & $19 \mathrm{~T}$ & $18 \mathrm{~T}$ & 0.947 \\
\hline
\end{tabular}

Selanjutnya adalah menguji gearbox close ratio tersebut dengan menggunakan rumus mencari toleransi nilai perbandingan rasio (nilai toleransi 0,025 ).

$$
\begin{aligned}
& -2,0754-2,0666=0,0088 \\
& -\quad 1,571-1,555=0,016 \\
& -1,341-1,333=0,008 \\
& -1,157-1,136=0,021 \\
& -1,000-1,000=0
\end{aligned}
$$

Tahap ketiga adalah melakukan pengecekan atau inspeksi pada jumlah mata roda gigi gearbox close ratio di setiap tingkat percepatan menggunakan metode kuantitatif dengan cara mencari datadata primer menggunakan rumus perhitungan, lalu dibandingkan dengan data sekunder yang telah diperoleh dari beberapa sumber sebelum dibuat bentuk fisik gearbox close ratio hasil modifikasi agar tidak terjadi kegagalan.

\subsection{Perakitan}

Perakitan adalah memasang gearbox close ratio di mesin (crankcase) sepeda motor Kawasaki Ninja RR 150cc dan melakukan setting/adaptability sepeda motor ketika menggunakan gearbox close ratio agar berfungsi dengan maksimal dalam meningkatkan performa akselerasi. Proses produksi dilakukan di Workshop Moto 1 CMS Racing yang beralamat di kawasan Kemayoran, Jakarta. Tahapan yang dilakukan di workshop. 
Modifikasi Gearbox Close Ratio Untuk Meningkatkan Akselerasi Sepeda Motor Kawasaki Ninja RR 150CC

- Membuat desain ukuran gearbox close ratio seluruhnya, sesuai dengan jumlah mata roda gigi yang sudah ditentukan.

- Menentukan bahan.

- Membuat bentuk wujud atau benda.

\subsection{Pengujian Performa Sepeda Motor}

Untuk menguji performa sepeda motor ada dua metode, yaitu dengan menggunakan mesin penguji dynotest dan pengujian langsung di lapangan (di jalan atau sirkuit yang aman untuk melakukannya). Untuk pengujian di lapangan terdapat acuan yang sering digunakan oleh hampir semua penguji, yaitu Top speed menguji di jalan yang memiliki jarak yang panjang dan tanpa hambatan (kurang lebih $1 \mathrm{~km}$ ).

Pengujian dynotest adalah melakukan test ride sepeda motor Kawasaki Ninja RR 150cc di atas mesin dyno test atau mesin pengetesan dengan dinamometer. Tempat pengujian dilakukan di Sportisi Motorsport, Rawamangun, Jakarta Timur. Mesin dynotest berjenis atau bertipe Dynojet 250i made in USA (Amerika Serikat). Cara pengujiannya adalah mencari kecepatan $(\mathrm{km} / \mathrm{jam})$ dalam perputaran mesin yang ditentukan (1100 rpm - $11000 \mathrm{rpm}$ ), dan shifting gear rpm. Dengan catatan, tidak semua gear speed dapat dilakukan pada beberapa putaran mesin.

Pengujian langsung di lapangan, tempat yang dipilih adalah Perumahan Kota Wisata Cibubur, Jl. Ruko Sentra Eropa. Alat pencatat waktu yang digunakan adalah stopwatch. Data yang dicari adalah waktu untuk meraih kecepatan dalam jarak 0-100 m dan 0-200 m.

Akselerasi: menguji dengan dua acuan.

- Waktu yang ditempuh dalam jarak 0-100 m dan 0-201 m.

- Waktu yang dibutuhkan untuk menggapai kecepatan sepeda motor 0-60 km/j dan 0-100 km/j. Alat-alat yang digunakan dalam pengujian.

1) Speedometer

Speedometer adalah sebuah alat pengukur kecepatan kendaraan darat, yang merupakan perlengkapan standar setiap kendaraan yang beroperasi di jalan.

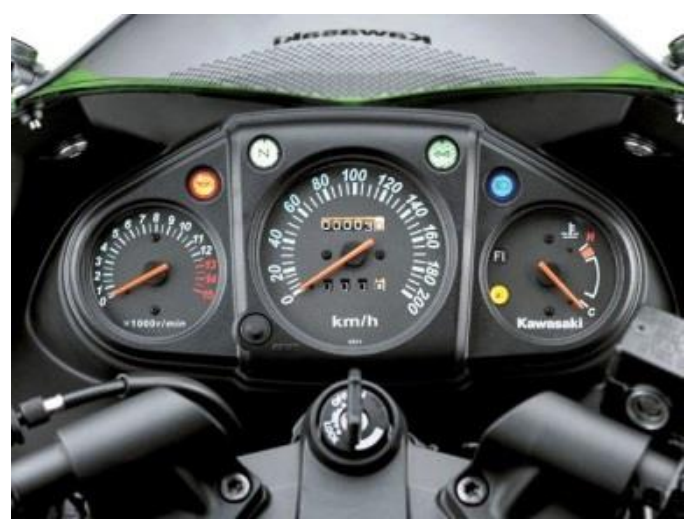

Gambar 2. Speedometer 
2) Tachometer

Tachometer adalah sebuah alat pengujian yang dirancang untuk mengukur kecepatan rotasi dari sebuah objek, seperti alat pengukur dalam sebuah sepeda motor yang mengukur putaran per menit (rpm) dari poros engkol mesin.[10]

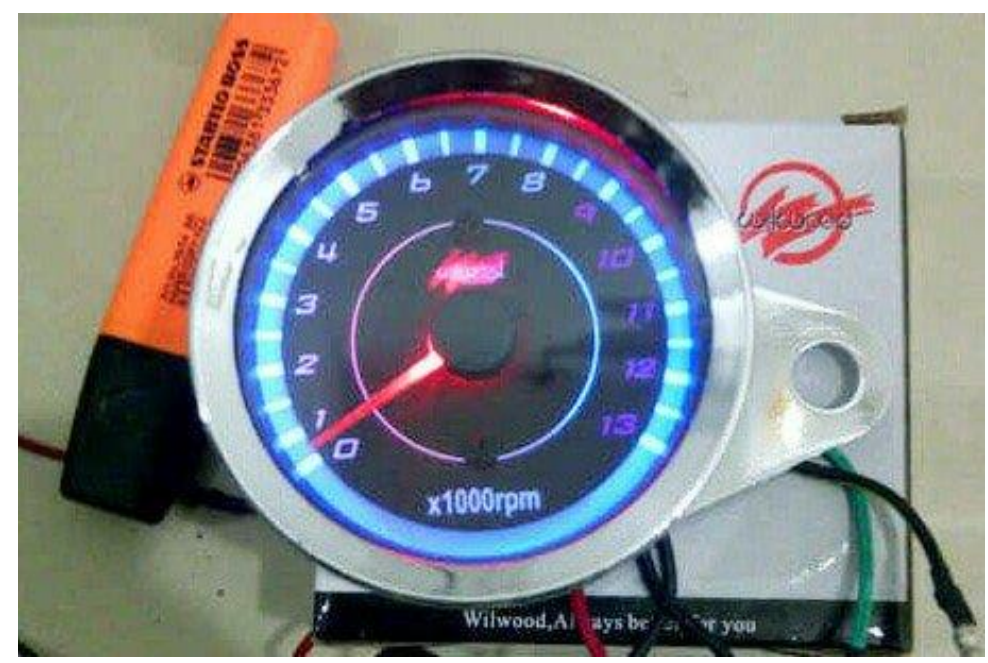

Gambar 3. Tachometer

3) Mesin Dynotest.

Dalam konteks automotive, Dynamometer atau dyno adalah alat ukur untuk mengetahui kekuatan yang dihasilkan oleh mesin kendaraan darat atau sering digunakan untuk sepeda motor atau mobil. Dynotest dapat mengenali atau mengetahui kekuatan yang dihasilkan oleh mesin sepeda motor, dengan hasil yang dikeluarkan berupa torsi perputaran mesin dan output power perputaran mesin, serta dapat mengetahui kecepatan maksimum. Juga dapat dikembangkan untuk mengetahui hal yang lain selama data-data tersebut tampil pada layar komputer dynotest, dan juga teknologi yang terdapat pada sepeda motor yang diuji. Running dynotest tidak hanya dilakukan pada posisi top gear, running dynotest dapat membaca pada setiap gigi selain netral.

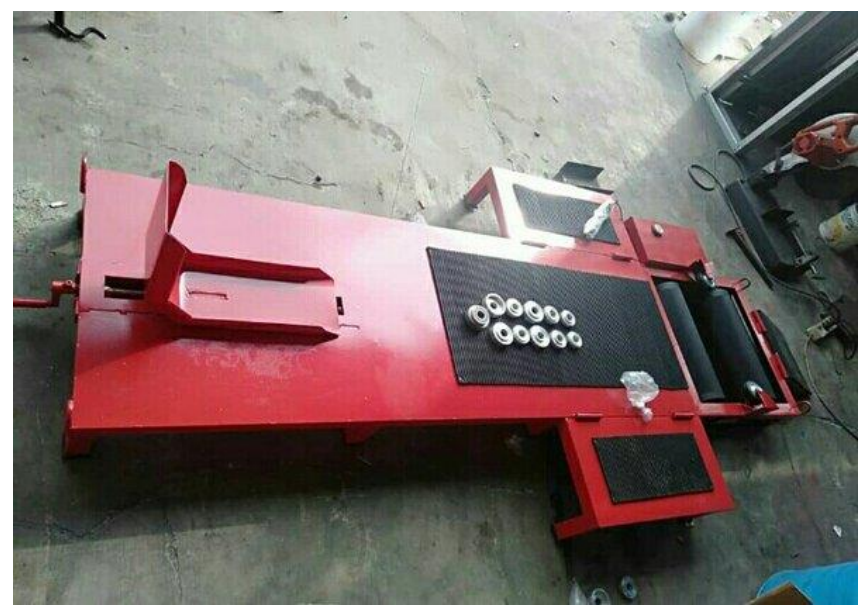

Gambar 4. Mesin Dynotest 
Modifikasi Gearbox Close Ratio Untuk Meningkatkan Akselerasi Sepeda Motor Kawasaki

Ninja RR 150CC

\section{HASIL DAN PEMBAHASAN}

3.1 Hasil Pengujian Mesin Dynotest

Dari penelitian yang yang sudah dilakukan didapat hasil seperti terlihat pada tabel 3. Pada putaran mesin 7000 rpm ke atas terlihat perbedaan kecepatannya sangat signifikan bila dibandingkan dengan data-data yang diperoleh dari hasil metode kuantitatif, dikarenakan pengaruh atau efek dari Super KIPS pada mesin sepeda motor Kawasaki Ninja RR 150cc yang dapat meningkatkan performa sebesar $10 \%-20 \%$.

Tabel 3. Kecepatan hasil dynotest gearbox standar

\begin{tabular}{cccccccccccc}
\hline Gear & $\mathbf{1 1 0 0}$ & $\mathbf{2 2 0 0}$ & $\mathbf{3 3 0 0}$ & $\mathbf{4 4 0 0}$ & $\mathbf{5 5 0 0}$ & $\mathbf{6 6 0 0}$ & $\mathbf{7 7 0 0}$ & $\mathbf{8 8 0 0}$ & $\mathbf{9 9 0 0}$ & $\mathbf{1 1 0 0 0}$ & \\
speed & rpm & rpm & $\mathbf{r p m}$ & $\mathbf{r p m}$ & $\mathbf{r p m}$ & $\mathbf{r p m}$ & $\mathbf{r p m}$ & $\mathbf{r p m}$ & $\mathbf{r p m}$ & $\mathbf{r p m}$ & \\
\hline 1 st & 6 & 11 & 16 & 22 & & & & & & & $\mathrm{Km} / \mathrm{jam}$ \\
2nd & 9 & 17 & 25 & 34 & 42 & 47 & 58 & & & & $\mathrm{Km} / \mathrm{jam}$ \\
3rd & & 15 & 33 & 44 & 55 & 62 & 80 & 95 & 105 & & $\mathrm{Km} / \mathrm{jam}$ \\
4th & & & 30 & 40 & 65 & 74 & 91 & 105 & 123 & 133 & $\mathrm{Km} / \mathrm{jam}$ \\
5th & & & & & 73 & 85 & 97 & 115 & 135 & 147 & $\mathrm{Km} / \mathrm{jam}$ \\
6th & & & & & & 92 & 105 & 122 & 147 & 165 & $\mathrm{Km} / \mathrm{jam}$ \\
\hline
\end{tabular}

Tabel 4. Kecepatan hasil dynotest gearbox modifikasi

\begin{tabular}{cccccccccccc}
\hline Gear & $\mathbf{1 1 0 0}$ & $\mathbf{2 2 0 0}$ & $\mathbf{3 3 0 0}$ & $\mathbf{4 4 0 0}$ & $\mathbf{5 5 0 0}$ & $\mathbf{6 6 0 0}$ & $\mathbf{7 7 0 0}$ & $\mathbf{8 8 0 0}$ & $\mathbf{9 9 0 0}$ & $\mathbf{1 1 0 0 0}$ & \\
speed & rpm & rpm & $\mathbf{r p m}$ & $\mathbf{r p m}$ & $\mathbf{r p m}$ & $\mathbf{r p m}$ & $\mathbf{r p m}$ & $\mathbf{r p m}$ & $\begin{array}{c}\text { rpm } \\
\text { rpm }\end{array}$ & \\
\hline 1 st & 8 & 15 & 22 & 27 & 34 & & & & & & $\mathrm{Km} / \mathrm{jam}$ \\
2nd & 10 & 20 & 28 & 37 & 45 & 55 & 62 & & & & $\mathrm{Km} / \mathrm{jam}$ \\
3rd & & 31 & 34 & 45 & 57 & 65 & 80 & 92 & 105 & & $\mathrm{Km} / \mathrm{jam}$ \\
4th & & & 32 & 42 & 67 & 75 & 90 & 102 & 120 & 126 & $\mathrm{Km} / \mathrm{jam}$ \\
5th & & & & & 75 & 85 & 98 & 115 & 130 & 143 & $\mathrm{Km} / \mathrm{jam}$ \\
6th & & & & & & 90 & 103 & 120 & 140 & 150 & $\mathrm{Km} / \mathrm{jam}$ \\
\hline
\end{tabular}

Selanjutnya dilakukan pengujian akselerasi. Caranya adalah sepeda motor Kawasaki Ninja RR $150 \mathrm{cc}$ melaju diatas mesin dynotest lalu dicatat waktu untuk meraih kecepatan, dalam 0 - $60 \mathrm{Km} / \mathrm{j}$ dan 0 - $100 \mathrm{Km} / \mathrm{j}$. Hasilnya dapat dilihat di tabel di bawah ini.

Tabel 5. Perbandingan waktu mencapai kecepatan

\begin{tabular}{ccc}
\hline AKSELERASI & GEARBOX STANDAR & $\begin{array}{c}\text { GEARBOX } \\
\text { MODIFIKASI }\end{array}$ \\
\hline $0-60 \mathrm{Km} / \mathrm{jam}$ & 3,5 detik & 2,7 detik \\
$0-100 \mathrm{Km} / \mathrm{jam}$ & 7,5 detik & 6,5 detik \\
\hline
\end{tabular}

Dari tabel 3 maka untuk memudahkan analisa dibuat sesuai dengan gambar 3. 


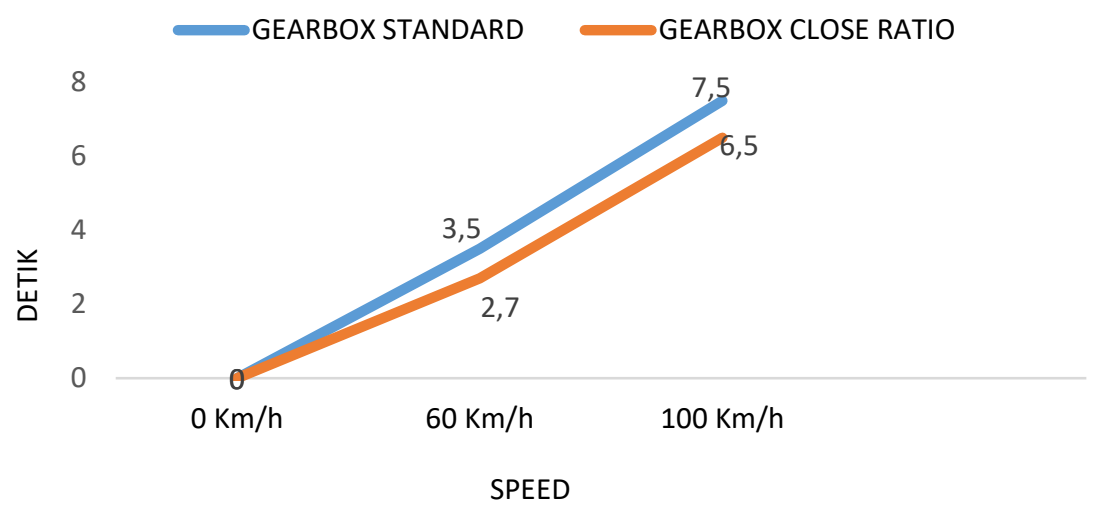

Gambar 3. Perbandingan Waktu Mencapai Kecepatan

\subsection{Hasil Pengujian di Jalan (On the road)}

Pelaksanaan pengujian ini adalah sepeda motor Kawasaki Ninja RR 150cc dikendarai untuk menganalisa akselerasi waktu tempuh menggapai jarak sepeda motor Kawasaki Ninja RR 150cc di jalanan. Dari penelitian yang telah dilakukan didapat hasil pada tabel 5.

Tabel 5. Perbandingan Waktu Menempuh Jarak

\begin{tabular}{|c|c|c|}
\hline JENIS & WAKTU TEMPUH 0 & - WAKTU TEMPUH 0- \\
\hline STANDAR & 6,2 detik & 10 detik \\
\hline MODIFIKASI & 5,1 detik & 9,5 detik \\
\hline
\end{tabular}

Dari tabel 5 maka untuk memudahkan analisa dibuat gambar 4.

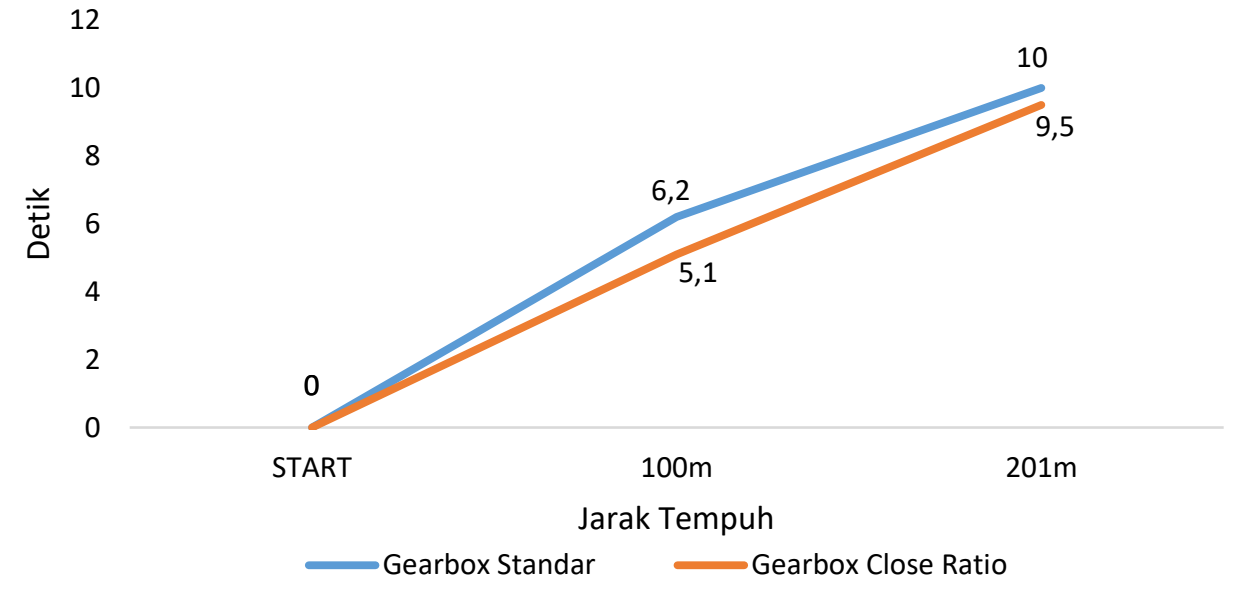

Gambar 4. Perbandingan waktu menempuh jarak

\section{SIMPULAN}

Gearbox hasil modifikasi telah memberikan hasil yang lebih baik dibanding dengan gearbox standar hal ini ditunjukkan dengan hasil pengujian yang telah dilakukan dengan menggunakan mesin uji dynotest maupun pengujian langsung di lapangan. Perbandingan waktu mencapai kecepatan dari hasil pengujian mesin uji dynotest menunjukkan bahwa untuk mencapai kecepatan $60 \mathrm{~km} / \mathrm{jam}$ dari kecepatan $0 \mathrm{~km} / \mathrm{jam}$ pada gearbox standar dibutuhkan waktu 3,5 detik, sedangkan pada gearbox 
modifikasi dibutuhkan waktu 2,7 detik. Untuk mencapai kecepatan $100 \mathrm{~km} / \mathrm{jam}$ dari kecepatan 0 $\mathrm{km} / \mathrm{jam}$ pada gearbox standar dibutuhkan waktu 7,5 detik sedangkan pada gearbox modifikasi dibutuhkan waktu 6,5 detik. Dari hasil pengujian di jalan didapat hasil bahwa waktu yang dibutuhkan untuk mencapai jarak 100 meter pada gearbox standar dibutuhkan waktu 6,2 detik, sedangkan pada gearbox modifikasi dibutuhkan waktu 5,1 detik. Untuk mencapai jarak 200 meter pada gearbox standar dibutuhkan waktu 10 detik sedangkan pada gearbox modifikasi dibutuhkan waktu 9.5 detik. Perlu diadakan penelitian lanjutan dengan mencoba pada speda motor dengan merek dan tipe lain yang lebih banyak digunakan oleh masyarakat Indonesia.

\section{DAFTAR PUSTAKA}

[1] Y. Herwangi, I. Syabri, and I. Kustiwan, "Peran dan Pola Penggunaan Sepeda Motor Pada Masyarakat Berpendapatan Rendah di Kawasan Perkotaan Yogyakarta," J. Perenc. Wil. dan Kota, 2015, doi: 10.5614/jpwk.2015.26.3.2.

[2] R. D. Dinye, "The significance and issues of motorcycle transport in the Urban areas in northern Ghana," Sci. J. Rev., 2013, doi: 10.14196/sjas.v2i10.1032.

[3] N. E. Jayanti, M. Hakam, and I. Santiasih, "EMISI GAS CARBON MONOOKSIDA (CO) DAN HIDROCARBON (HC) PADA REKAYASA JUMLAH BLADE TURBO VENTILATOR SEPEDA MOTOR 'SUPRA X 125 TAHUN 2006,"” ROTASI, 2014, doi: 10.14710/rotasi.16.2.1-5.

[4] BPS, "Perkembangan Jumlah Kendaraan Bermotor Menurut Jenis," Badan pusat statistik. 2019.

[5] W. kristian, denny, rita, "Keputusan Pembelian Sepeda Motor Honda Pada Mahasiswa Kampus 1 Universitas Kristen Krida Wacana,” J. Ilm. Manaj. Bisnis, 2016.

[6] J. Sepang and G. Joel, "PENGARUH MOTIVASI, PERSEPSI HARGA, DAN KUALITAS PRODUK TERHADAP MINAT BELI KONSUMEN SEPEDA MOTOR MATIC MEREK YAMAHA MIO DI KOTA MANADO,” J. Ris. Ekon. Manajemen, Bisnis dan Akunt., 2014, doi: 10.35794/emba.v2i3.5895.

[7] U. S. Dharma and T. H. Wahyudi, "PENGARUH VOLUME RUANG BAKAR SEPEDA MOTOR TERHADAP PRESTASI MESIN SEPEDA MOTOR 4-LANGKAH,” Turbo J. Progr. Stud. Tek. Mesin, 2017, doi: 10.24127/trb.v4i2.77.

[8] H. Razali, K. Sopian, S. Mat, and S. Ibrahim, "Modification of motorcycle with hydrogen mixture and effect on emission," ARPN J. Eng. Appl. Sci., 2015.

[9] E. Nahartyo, Desain dan Implementasi Riset Eksperimen. 2012.

[10] E. Enny, "Tachometer Laser , Pemakaian Dan Perawatannya," METANA, 2018, doi: 10.14710/metana.v13i1.12578. 